Faculdade de Ciências Econômicas da UFRGS
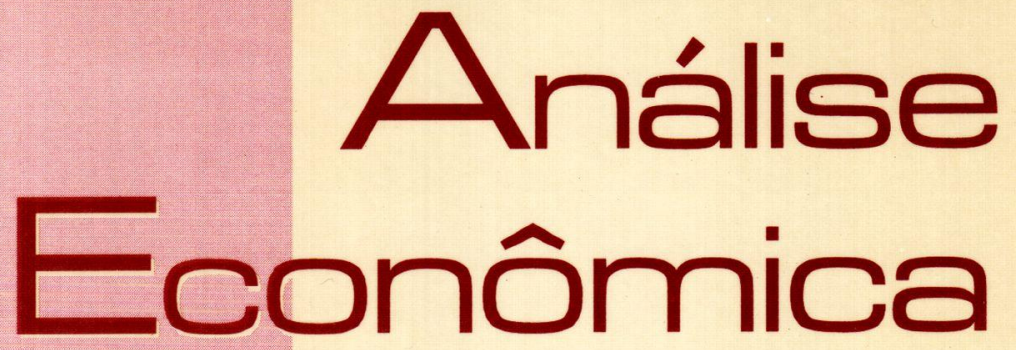

A Instabilidade Financeira dos Anos 90: Alqumas Implicações para as Economias Capitalistas Periféricas André Cunha e Daniela Prates

A Ampliação Recente da Participação Estrangeira no Sistema Bancário Brasileiro Maria Cristina Penido de Freitas

INFRA-ESTRUTURA dE INfORMAÇÕES E SISTEMA Nacional de InOvação

Eduardo da Motta e Albuquerque

Custo Social dos Recursos Hídricos em Bacias Hidrográlicas Internacionais: O Caso da Bacia do Paraná Jandir Ferrera de lima e José Carrera-Fernandez

Preferência pela liovidez e Escollha de Porrtólio

José Luis Oreiro

Eficiência, Objetivo e Coordenação da Política Macroeconômica no Período: 1974 - 1979

JoÃo Sicsú

Macroeconomia Moderna: Keynes e a ECONOMIA CONTEMPORÂNEA - Resenha

Simone Silva de Deos

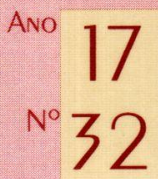


Universidade Federal do Rio Grande do Sul

Reitora: Proft. Wrana Maria Panizzi

Faculdade de Ciências Econômicas

Diretora: Prof ${ }^{a}$. Otilia Beatriz Kroeff Carrion

Centro de Estudos e Pesquisas Econômicas

Diretor: Prof. Fernando Ferrari Filho

Departamento de Ciencias Econômicas

Chefe: Prof Luiz Alberto Oliveira Ribeiro de Miranda

Curso de Pós-Graduação em Economia

Coordenador: Prof. Marcelo Savino Portugal

Curso de Pós-Graduaçāo em Economia Rural

Coordenador: Prof. Carlos Guilherme A. Mielitz Netto

Conselho edtrorial

Achyles B. Costa, Aray M. Feldens, Carlos A. Crusius, Carlos G. A. Mielitz Netto, Eduardo A. Maldonado Filho, Eduardo P. Ribeiro, Eugênio Lagemann, Fernando Ferrari Filho, Gentil Corazza, Marcelo S. Portugal, Nali J. Souza, Otilia B. K. Carrion, Paulo A. Spohr, Paulo D. Waquil, Pedro C. D. Fonseca, Roberto C. Moraes, Ronald Otto Hillbrecht, Stefano Florissi, Eleutério F. S. Prado (USP), Fernando H. Barbosa (FGV/RJ), Gustavo Franco (PUC/RJ), João R Sanson (UFSC), Joaquim P. Andrade (UnB), Juan H. Moldau (USP), Paul Davidson (Univ. of Tennessee), Werner Baer (Univ. of Illinois).

Comissão EDITORLAL

Eduardo Augusto Maldonado Filho, Fernando Ferrari Filho, Gentil Corazza, Marcelo Savino Portugal, Paulo Dabdab Waquil; Roberto Camps Moraes.

EDrTor: Gentil Corazza

Edrror Adjunto: Pedro Silveira Bandeira

SeCretaria: Laize Espindula.

REVISÃo DE TEXTos: Vanete Ricacheski.

Fundador: Prof. Antônio Carlos Santos Rosa

Os materiais publicados na revista Análise Econômica são da exclusiva responsabilidade dos autores. É permitida a reprodução total ou parcial dos trabalhos, desde que seja citada a fonte. Aceita-se permuta com revistas congêneres. Aceitam-se, também, livros para divulgação, elaboração de resenhas e recensões. Toda correspondência, material para publicação (vide normas na terceira capa), assinaturas e permutas devem ser dirigidos ao seguinte destinatário:

Prof, Gentul Corazza

Revista Análise Econômica - Av. João Pessoa, 52 CEP 90040-000 PORTO ALEGRE - RS, BRASIL

Telefones: 0xx (51) 316-3348 e 316-3440 - Fax: 0xx (51) 316-3990 rae@vortex.ufrgs.br

Análise Econômica

Ano 17, n. 32, setembro, 1999 - Porto Alegre

Faculdade de Ciências Econômicas, UFRGS, 1999

Periodicidade semestral, março e setembro.

ISSN 0102-9924

1. Teoria Econômica - Desenvolvimento Regional -

Economia Agrícola - Pesquisa Teórica e Aplicada -

Periódicos. I. Brasil.

Faculdade de Ciências Econômicas,

Universidade Federal do Rio Grande do Sul.

CDD 330.05

CDU 33 (81) (05) 


\title{
Preferência pela liquidez e escolha de portfolio Estabelecendo os micro fundamentos da não-neutralidade da moeda no longo prazo*
}

\author{
José Luis Oreiro **
}

\begin{abstract}
Sinopse :Neste artigo apresentamos um modelo formal de escolha de portfólio baseado no capítulo 17 da Teoria Geral de Keynes, com o objetivo de demonstrar que a política monetária pode ser não-neutra no longo-prazo caso os indivíduos valorizem a posse de ativos líquidos em seus portfólios. Nesse contexto, se as autoridades monetárias realizarem operações de open-market com o objetivo de aumentar o estoque de ativos líquidos existentes na economia; irá ocorrer um aumento do preço spot dos ativos de capital. Na medida em que a decisão de investimento das firmas é tomada com base na comparação entre o preço spot e o preço forward dos ativos em consideração, tal aumento irá induzi-las a investir mais e, conseqüentemente, irá aumentar o estoque de capital de equilíbrio de longo prazo da economia em consideração.
\end{abstract}

Palavras-chave: Preferência pela liquidez, incerteza e política monetária.

\begin{abstract}
This article presents a formal model of portfolio selection inspired in the chapter 17 of Keynes's General Theory in order to show that monetary policy can be non-neutral in the long-run if agents desire to hold liquid assets in their portfolios. In this case, if monetary authorities do open market operations with the purpose of increase the stock of liquid assets in the economy, then the spot price of capital goods will increase . Since firm's investment decisions depends on the comparasion between spot and forward price of this kind of assets; such increase will induce more investment, resulting in an increase of long run equilibrium capital stock of the economy.
\end{abstract}

Key words: Liquidity preference, uncertainty and monetary policy.

\section{Introdução}

A teoria Keynesiana é geralmente acusada por seus críticos de não possuir sólidos fundamentos microeconômicos, ou seja, ela se basearia em hipóteses que não são compatíveis ou, ao menos explicitamente, deduzidas a partir do comportamento otimizador individual. Segundo essa linha de crítica à teoria Keynesiana, os principais resultados teóricos propostos por Keynes, a saber, o

\footnotetext{
${ }^{*} \mathrm{O}$ autor agradece os comentários e sugestões dos Profs. Drs. Fernando Cardim de Carvaiho e Antônio Luiz Licha, bem como dos pareceristas que avaliaram o presente artigo. Eventuais falhas são, contudo, de minha inteira responsabilidade

** Doutorando em Economia (IE-UFRJ) e Professor Assistente da Faculdade de Economia e Finanças do Instituto Brasileiro de Mercado de Capitais (IBMEC)[E-Mail: oreiro@ibmec.br]
} 
desemprego involuntário da força de trabalho e a não-neutralidade da moeda no longo prazo, só seriam sustentáveis por intermédio da adoção de hipóteses ad hoc a respeito do comportamento individual. Em concreto, o desemprego involuntário da força de trabalho seria o resultado da hipótese de que os trabalhadores resistem a reduções de salário nominal e não a reduções de salário real (Pigou, 1943; Modigliani, 1944) ${ }^{1}$; ao passo que a não-neutralidade seria o resultado do fato de que a taxa nominal de retorno sobre a moeda é fixada em nível istitucional, de forma que seria impossível o ajuste de todas as variáveis nominais da economia a uma variação na oferta de moeda (Cf. Tobin, 1969) mesmo no longo prazo. Entretanto nenhum desses dois elementos pode ser diretamente explicado a partir do comportamento otimizador individual.

Para alguns Keynesianos, a suposta incompatibilidade entre os resultados teóricos propostos por Keynes e a hipótese de racionalidade substantiva utilizada pela teoria econômica convencional não se constitui num problema teórico para a agenda de pesquisa Keynesiana. De fato, para esses autores a economia Keynesiana estaria fundamentada na hipótese de racionalidade limitada, não na hipótese de racionalidade substantiva. Como é bem-sabido, a distinção entre racionalidade substantiva e racionalidade limitada é devida a Simon (1982). Segundo esse autor, num ambiente caracterizado pela existência de complexidade nos processos de tomada de decisão (complexidade essa advinda que pode resultar, por exemplo, da existência de interação estratégica entre os agentes econômicos tal como é suposto na Teoria dos Jogos) não é razoável supor que os agentes possuem a capacidade cognitiva necessária para a maximização de uma função objetivo. A capacidade cálculo dos agentes é limitada, sendo assim, a racionalidade dos agentes econômicos irá se expressar através do emprego de rotinas e processos de tomada de decisão que economizem no uso da capacidade de cálculo por parte dos indivíduos.

Independentemente dos méritos ou deméritos desse tipo de abordagem para a questão da racionalidade dos agentes econômicos, é um fato incontestável que qualquer teoria econômica tem que estar apoiada em algum suposto a respeito da forma pela qual os agentes tomam suas decisões. Simplesmente não é razoável se considerar que os agregados macroeconômicos (consumo, investimento, renda, emprego, etc.) não são, em larga medida, o resultado agregado das decisões tomadas por uma multidão de agentes econômicos.

Nesse contexto, pretendemos demonstrar ao longo do presente artigo que a proposição de Keynes de que a moeda é não-neutra no longo prazo é plenamente compatível com o suposto tradicional de maximização de uma função objetivo.

\footnotetext{
${ }^{1}$ Oreiro (1997) demonstra que a flexibilidade de salários nominais não garante a convergência das economia de mercado a posição de equilíbrio com pleno-emprego. Sendo assim, a rigidez de salários nominais, ainda que seja um fenômeno observado empiricamente, não é o fator responsável pela ocorrência de desemprego involuntário da força de trabalho.
} 
De fato, a teoria Keynesiana da escolha de portfólio, exposta no capítulo 17 da Teoria Geral do Emprego, do Juro e da Moeda, apresenta como um dos seus principais resultados o fato de que as variações do estoque de moeda são capazes de influenciar o estoque de capital de equilíbrio de longo prazo da economia ${ }^{2}$. Isso porque, num contexto de incerteza do tipo Knight-Keynes, a moeda pode ser demandada como um ativo por parte dos agentes econômicos, de forma que ela passa a concorrer com outros ativos, entre eles o capital, pela preferência dos agentes no processo de determinação da composição de portfólio dos mesmos (cf. Studart, 1995, p.28). Em outras palavras, a não-neutralidade da moeda no longo prazo $^{3}$ decorre do fato de que moeda e capital são substituíveis entre si no portfólio dos indivíduos. Essa substitubilidade, por outro lado, não resulta de nenhum tipo de "miopia" por parte dos agentes econômicos, mas sim do fato de que em um ambiente caracterizado pela presença de incerteza, estes podem valorizar a posse de ativos líquidos, atribuindo um "prêmio de liquidez" a moeda. Dessa forma, a moeda apresentaria um retorno implícito que concorre com o retorno explícito proporcionado pelos ativos de capital. Um aumento da quantidade de moeda existente na economia pode fazer com que os agentes econômicos valorizem menos a posse de ativos líquidos, deslocando, portanto, a sua demanda em direção a outros ativos, em particular, os ativos de capital. Segue-se, portanto, que a não-neutralidade da moeda é o resultado da preferência pela liquidez.

\footnotetext{
${ }^{2}$ Ao longo do presente artigo estaremos utilizando os termos curto e longo prazos no sentido Marshalliano, ou seja, curto prazo corresponde a uma situação na qual o estoque de capital é constante, ao passo que longo prazo corresponde a uma situação na qual tal estoque é variável. Deve-se observar que tais definições contrastam fortemente com o sentido no qual tais termos são usados pela macroeconomia convencional, em particular, pelos modelos do tipo ISLM. De fato, em tais modelos o curto prazo é definido como uma situação na qual os preços nominais são rígidos (cf. McCaliun, 1996, p. 121), de forma que a economia pode se encontrar fora da posição de equilíbrio com plenoemprego. Já o longo prazo é uma situação na qual os preços nominais são perfeitamente flexíveis de forma que a economia estará operando em equilíbrio com pleno-emprego. No entanto, em ambos os casos se supõe uma situação na qual o estoque de capital é constante; de forma que o equilibrio definido pelos referidos modelos é essencialmente uma posição de curto prazo no sentido Marshalliano. Para os objetivos deste artigo, o que interessa é analisar os efeitos da política monetária sobre o estoque de capital de equilíbrio de longo prazo no sentido Marshalliano, deixando de lado as repercussôes que a mesma tem sobre o nivel de emprego de equilíbrio.

${ }^{3}$ Deve-se ter em mente que o conceito de não-neutralidade da moeda no longo prazo empregado nos modelos pósKeynesianos é diferente do conceito de não-neutralidade da moeda empregado nos modelos macroeconômicos de cunho neoclássico. Em tais modelos a moeda é dita não-neutra no longo prazo se, num contexto em que os preços são instantaneamente flexíveis, uma variação do tipo once-and-for-all do estoque nominal de moeda tiver efeito sobre as variáveis reais da economia, como, por exemplo, a renda real (cf. McCallun, 1996, p.113). Já nos modelos pósKeynesianos a moeda é dita não-neutra no longo prazo se uma variação do tipo once-and-for-all do estoque de moeda tiver efeito sobre o estoque de capital de equilibrio de longo prazo dados os preços de todos os demais bens e ativos dessa economia. Essa diferença na conceituação do que vem a ser não-neutralidade da moeda no longo prazo radica não só nas diferenças existentes entre os modelos pós-Keynesianos e os modelos macroeconômicos neoclássicos no que se refere aos conceitos de curto e longos prazos (ver nota 2), como também nas diferenças do método de análise empregado em cada um dos diferentes tipos de modelos. Enquanto os modelos neoclássicos se utilizam do método de equilíbrio geral popularizado por Hicks no seu artigo clássico de 1937; os modelos pós-Keynesianos se baseiam no método de equilíbrio parcial Marhalliano (cf. Davidson, 1978).
} 
Com base nesse objetivo, o presente artigo está estruturado da seguinte forma:

Na primeira seção apresentaremos uma versão sofisticada do modelo de escolha de portfólio de Keynes exposto no capítulo 17 da Teoria Geral. Nesse modelo será analisada a decisão individual de alocação de riqueza entre dois ativos, moeda e capital. Será demonstrado então que a alocação do estoque de riqueza entre os ativos em consideração irá depender, entre outras variáveis, do prêmio de liquidez da moeda, o qual define a taxa subjetiva de juros que os agentes irão utilizar para calcular o preço de demanda dos bens de capital, ou seja, o preço máximo que os agentes estão dispostos a pagar por uma unidade de capital. A partir desse preço de demanda, iremos definir a função de demanda individual de capital, a qual em conjunto com o preço de mercado desse ativo irá determinar a quantidade de capital que os indivíduos desejam reter em seus portfólios.

Na segunda seção, passaremos a questão da determinação do preço de mercado dos bens de capital. Tomaremos, então, o estoque de capital agregado como um dado (curto prazo marshalliano), e agregaremos as funções de demanda individuais de capital com o objetivo de obter a função de demanda agregada de capital. O preço spot dos ativos de capital será determinado no ponto em que a demanda agregada de capital for igual ao estoque disponível do mesmo. A relação entre o preço spot do capital e o seu custo de reposição nos fornece a variável $q$ de Tobin; sendo assim, no equilíbrio de curto prazo do modelo em consideração, estaremos determinando não só o preço spot dos ativos de capital, como também o volume de investimento desejado pelos empresários.

Ainda na segunda seção, analisaremos o impacto que a política monetária tem sobre o equilíbrio de longo prazo dessa economia. A condição de equilíbrio de longo prazo é definida pela igualdade entre o preço spot dos ativos de capital e o seu custo de reposição. Será demonstrado então que uma política monetária expansionista conduzida por intermédio de operações de open-market é capaz de aumentar o estoque de capital de equilíbrio de longo prazo dessa economia, caracterizando, portanto, a não-neutralidade da moeda.

A terceira seção sumariza as conclusões obtidas ao longo do presente artigo.

\section{A teoria Keynesiana da escolha de Portfólio: 0 modelo de taxa própria de juros}

\subsection{Incerteza e preferência pela liquidez}

No capítulo 17 da Teoria Geral, Keynes apresenta os fundamentos de sua teoria da escolha de portfólio. Segundo Keynes, todos os ativos existentes em uma economia possuiriam os seguintes atributos em maior ou menor grau: 
1. Quase - rendas: receitas monetárias advindas da utilização de um ativo no processo de produção (lucros) ou da simples posse do mesmo (juros e dividendos).

2. Custo de manutenção: rendimentos negativos associados à manutenção do ativo em consideração no portfólio dos agentes. Tratase do custo de estocagem do ativo, não tendo nenhuma relação com os custos resultantes da utilização do ativo no processo produtivo, ou seja, com aquilo que Keynes denominou de custo de uso do capital.

3. Prêmio de Liquidez: refere-se à "conveniência" e segurança potenciais associados à presença de um ativo no portfólio dos agentes.

4. Ganhos ou perdas esperados de capital: são os retornos que o investidor espera obter no momento em que ele decide vender os ativos que possui em portfólio. No momento da realização desses ativos, podem ocorrer perdas ou ganhos de capital relativamente ao preço que o investidor pagou pelo referido ativo. As expectativas a respeito da obtenção de ganhos ou perdas esperados de capital sobre a revenda de um ativo pode ser extremamente importante no momento em que o investidor está decidindo a compra de um determinado ativo.

De todos esses atributos, o "prêmio de liquidez" é, de longe, o atributo que mais diferencia a teoria de escolha de portfólio de Keynes das teorias convencionais. De fato, as teorias convencionais de composição de portfólio admitem que certos ativos devem pagar um "prêmio de risco" para os investidores, de forma a compensá-los pelo maior risco associado à posse desses ativos ${ }^{4}$. Em outras palavras, em equilíbrio, ativos mais arriscados devem proporcionar uma taxa de retorno maior do que ativos menos arriscados. $\mathrm{O}$ risco associado à posse de um ativo pode ser de dois tipos (Kahn, 1954): risco-renda, ou seja, o risco referente à ocorrência de variações não-previstas no rendimento dos ativos; risco-capital, isto é, o risco referente à possibilidade de ocorrência de reduções inesperadas dos preços dos ativos ${ }^{4}$. Via de regra, indivíduos diferentes terão "preferências" diferentes a respeito desses dois tipos de risco; no entanto, ceteris paribus, quanto maior for o risco de um ativo maior deve ser a sua taxa de retorno para que os indivíduos se sintam estimulados a manter tais ativos em seus portfólios.

O "prêmio de liquidez" não é equivalente ao "prêmio de risco". A liquidez de um ativo não é medida pelo risco de perda de capital associado à posse de um

\footnotetext{
${ }^{4}$ Um exemplo de abordagem convencional é o modelo de Tobin (1958) de demanda de moeda como comportamento face ao risco. No modelo de Tobin, os indivíduos devem escolher entre dois ativos, moeda e títulos (consols), sendo que os títulos estão sujeitos a perda de capital ao longo do seu período de retenção, ao passo que a moeda não está sujeita a esse risco. Nesse contexto, os indivíduos só estarão dispostos a reter títulos em seus portfólios se estes proporcionarem uma taxa esperada de retorno maior do que a taxa de retorno sobre a posse de moeda; dado o maior risco associado a retenção de títulos visà-vis a retenção de moeda. Sendo assim, a maior rentabilidade dos títulos em comparação a rentabilidade da moeda deve ser entendida como um "prêmio de risco", ou seja, um retorno adicional que é necessário para compensar os agentes pelo maior risco associado à posse de títulos em seus portfólios.
} 
determinado ativo, ou seja, um ativo não é menos líquido do que outro só porque se antecipa que o preço pelo qual se poderá vender esse ativo no futuro é menor do que o seu preço de compra. A liquidez de um ativo deve ser medida pela facilidade com que tais ativos podem substituir a moeda como meio de pagamento (Cf. Macedo e Silva, 1994), isto é, pela capacidade de conversão de um ativo em dinheiro. Definida dessa forma, a liquidez é um conceito bidimencional (Cf. Carvalho, 1992). Por um lado, um ativo será tão mais líquido quanto mais rapidamente esse ativo puder ser convertido em meio de pagamento. Está claro que qualquer ativo pode ser convertido rapidamente em meio de pagamento se o preço de venda do mesmo for suficientemente baixo. Chegamos assim a segunda dimensão da liquidez, a saber: o custo envolvido no processo de transformação desse ativo em dinheiro. Nesse caso, um ativo será tão mais líquido quanto maior for o preço de realização desse ativo relativamente ao preço que poderia ser obtido caso se desse um prazo maior para a realização do mesmo (Cf. Hicks, 1988, p.226). Agregando-se essas duas dimensões da liquidez num único conceito, podemos afirmar, com base em Hicks, que um ativo será tão mais líquido quanto menor for a influência do prazo de realização desse ativo sobre o seu preço de venda .

A liquidez, portanto, é um atributo que confere grande flexibilidade a estrutura de portfólio dos indivíduos. De fato, quanto maior for a quantidade de ativos altamente líquidos que os indivíduos possuírem em seus respectivos portfólios tanto mais facilmente poderão mudar a composição dos mesmos quando e se o desejarem (Cf. Hicks, 1974; Vercelli, 1991). A flexibilidade será uma característica desejada pelos indivíduos unicamente em contextos nos quais os agentes sabem que poderão mudar a composição de seus portfólios no futuro. Isso irá ocorrer toda a vez que os agentes souberem que no futuro irão possuir mais informação a respeito da rentabilidade esperada dos diferentes ativos do que tem hoje, ou seja, quando os agentes souberem que não possuem hoje toda a informação a respeito da rentabilidade futura dos ativos em consideração (Cf. Vercelli, 1997, p.8). Um ambiente no qual os agentes não têm toda a informação de que necessitam para avaliar a rentabilidade esperada dos diferentes ativos é um ambiente no qual prevalece a incerteza Knight-Keynes (incerteza forte); a qual é definida como uma situação na qual os agentes não são capazes de definir uma lista completa de eventos ou estados da natureza que podem ocorrer no futuro ${ }^{5}$, de forma que as probabilidades de ocorrência dos referidos eventos são subaditivas, ou seja, sua soma é inferior a um (Cf. Vercelli, 1997, p.5).

\footnotetext{
${ }^{5}$ Isso resulta do fato de que uma parte considerável dos elementos do conjunto de estados da natureza é constituído por expectativas a respeito das decisões que outros indivíduos estão tomando ou irão tomar no futuro. Tais decisões, por sua vez, não são um dado; mas dependem em parte das expectativas que tais agentes formam a respeito da decisão que o primeiro irá tomar; de forma que nos deparamos com um problema de regressão infinita, o qual indetermina os elementos do referido conjunto (cf. Oreiro, 1998).
} 
Num contexto de incerteza, portanto, os agentes desejarão manter algum nível de flexibilidade na sua estrutura de portfólio; para tanto, desejarão reter uma parte de sua riqueza sob a forma de ativos líquidos, isto é, estarão dispostos, até certo ponto, a sacrificar a possibilidade de ter um maior retorno monetário em troca da posse de liquidez. Em outras palavras, os ativos menos líquidos deverão proporcionar aos seus proprietários uma taxa de retorno mais elevada de forma a compensá-los por sua menor liquidez. Chegamos assim a definição do conceito de "prêmio de liquidez", a saber: consiste no retorno implícito (subjetivo) que os indivíduos atribuem à posse de ativos líquidos ${ }^{6}$.

\subsection{O Modelo de Taxa Própria de Juros ${ }^{7}$}

Consideremos uma economia que possua apenas dois ativos, moeda $\mathrm{e}$ capital. $\mathrm{O}$ ativo capital é um agregado de diferentes ativos com diferentes graus de liquidez, sendo que a liquidez média desses ativos é inferior à liquidez do ativo moeda ${ }^{8}$. O capital é um ativo que pode ser utilizado na processo de produção de bens e serviços, proporcionando, portanto, uma quase-renda $\left(\mathrm{Q}_{\mathrm{k}}^{\prime}\right)$ ao seu proprietário ${ }^{9}$. Esse ativo possui um custo de retenção igual a $\mathrm{C}_{\mathrm{k}}$ por unidade de capital, um "prêmio de liquidez" igual a $l_{k}$ por unidade de capital e um prêmio de risco igual a $R_{k}$.

A quase-renda por unidade de capital nada mais é do que uma estimativa que os empresários fazem a respeito do retorno que poderão obter com a utilização desse ativo no processo de produção ao longo de um determinado período de tempo. Num ambiente marcado pela presença de incerteza forte, tais estimativas não são totalmente confiáveis, uma vez que os empresários têm ciência de que não dispõem de toda a informação necessária para construir a distribuição de probabilidades dos rendimentos futuros desse ativo. Sendo assim, as suas estimativas a respeito da rentabilidade futura desse ativo devem

\footnotetext{
"Kregel (1998) define o "prêmio de liquidez" da moeda como sendo equivalente ao seu "custo de uso", ou seja, o valor presente do ganho potencial futuro ou da perda que pode ser evitada se o agente preferir adiar suas decisões de gasto. Em outras palavras, o prêmio de liquidez da moeda surge quando o valor para o agente de uma decisão tomada em $t$ é menor do que o valor dessa mesma decisão adiada por $T$ períodos, ou seja, tomada em $\mathrm{t}+{ }^{\prime} \mathrm{T}$.

${ }^{7}$ O modelo apresentado a seguir é inspirado em Licha (1990),

${ }^{8}$ Essa hipótese corresponde à estrutura de agregação assumida por Keynes nos capítulos 13 e 15 da Teoria Geral onde capital e títulos da dívida pública são tidos substitutos perfeitos entre si Devemos ressaltar a diferença entre essa estrutura de agregação e a estrutura do modelo moeda-capital de Tobin, no qual se supõe que moeda e títulos da dívida pública são substitutos perfeitos entre si. Nesse caso, como ressalta Tobin (1969), não haveria espaço para a política monetária tal como é entendida usualmente, ou seja, como operações de open-market nas quais se realizam a troca de moeda por títulos do governo. Ao se supor que capital e títulos públicos são substitutos perfeitos, tal como estamos fazendo no presente artigo, abre-se espaço para a política monetária ao mesmo tempo em que se simplifica a estrutura formal do modelo.

${ }^{9}$ Para simplificar a apresentação do modelo, iremos considerar que a apreciação esperada dos ativos de capital está embutida na sua "quase-renda".
} 
ser ponderadas pelo grau de confiança que eles têm em suas próprias previsões (Cf. Carvalho, 1992, pp.84-85) ${ }^{10}$. Temos, então, que :

$$
Q_{k}^{\prime}\left(K_{i}\right)=\Phi Q_{k}\left(K_{i}\right) ; \partial Q^{\prime}\left(K_{i}\right) / \partial K_{i}<0
$$

onde : Fé o grau de confiança dos agentes em suas previsões a respeito do futuro; $Q_{k}$ representa as estimativas dos agentes a respeito da rentabilidade futura do ativo capital; $\mathrm{e} \mathrm{K}_{\mathrm{i}} \mathrm{e}$ a quantidade de capital que o indivíduo i possui em portfólio.

Observa-se na equação (1) que a quase-renda por unidade de capital é uma função decrescente da quantidade de capital que o indivíduo i possui em portfólio. Isso é uma decorrência do "princípio da rentabilidade esperada decrescente" (Macedo e Silva, 1994). As quase-rendas esperadas se reduzem à medida que os indivíduos aumentam a quantidade de capital em seus portfólios porque a "escassez" do capital se reduz com o aumento de sua quantidade. Deve-se observar, contudo, que a "escassez" de capital aqui definida nada tem a haver com a "escassez" no sentido neoclássico do termo. A "escassez" de capital nos modelos neoclássicos é definida com relação à quantidade do fator de produção trabalho existente na economia. Para Keynes, o capital é escasso com relação ao tamanho do mercado. Se as firmas estiverem operando com plantas muito reduzidas e com um pequeno volume de produção, então a demanda insatisfeita pelos produtos dessa firma irá se expressar em preços e margens de lucro bastante elevadas. Com o aumento da capacidade de produção das firmas - supondo que elas se defrontam com uma curva de demanda negativamente inclinada pelos seus produtos, ou seja, que prevalece a concorrência imperfeita no mercado de bens - os preços e as margens de lucro irão se reduzir, dando origem a quase-rendas decrescentes.

Como o capital, neste modelo, se constitui num agregado de ativos com diferentes graus de liquidez segue-se que tal agregado deve possuir um "prêmio de liquidez" positivo. Contudo, esse ativo é menos líquido do que a moeda, logo o seu "prêmio de liquidez" deve ser apenas uma fração do "prêmio de liquidez" desta última. Essa hipótese pode ser formalizada pela seguinte equação :

$$
I_{k}=\gamma I_{m}, \quad 0<\gamma<1
$$

\footnotetext{
${ }^{10}$ Segundo Vercelli (1997), o grau de confiança dos agentes em suas previsões está relacionado com o grau de nãoaditividade da distribuição de probabilidades relevante para o problema em consideração. De fato, o grau de confiança nada mais é do que aquilo que Keynes (1921) havia definido como "peso do argumento". O peso de um argumento $\mathrm{x} / \mathrm{h}$ - ou seja, o conjunto $\mathrm{x}$ de resultados obtidos a partir do conjunto h de hipóteses - é definido como $\mathrm{V}(\mathrm{x} / \mathrm{h})=\mathrm{K} /(\mathrm{K}$ $+M$ ), onde Ké a informação relevante possuída pelo agente e $M$ é a informação que o agente não possui, Obviamente que $M+K=1$. $O$ grau de não aditividade da distribuição de probabilidade é definido como c $(P, A)=1-P(A)-P\left(A^{c}\right.$ ), onde $A$ é um evento e $A^{c}$ o seu complementar. É intuitivo que $c(P, A)=M /(M+K)$, de onde concluímos que $v(x)$ h) $=1$ - c (P, A ) Em palavras: quanto maior for o grau de não aditividade da distribuição de probabilidades menor será a confiança que os agentes terão em suas previsc̃es, ou seja, menor será o peso do argumento (Vercelli, 1997, pp.4-5)
} 
Por fim, o ativo capital possui um prêmio de risco $\mathrm{R}_{\mathrm{k}}$, o qual será tido como uma função crescente em $\mathrm{K}_{\mathrm{i}}$, ou seja, quanto maior for a quantidade de capital possuída pelo indivíduo i maior será o "prêmio de risco do capital". Isso decorre do "princípio do risco financeiro crescente" (Cf. Kalecki, 1954), segundo o qual quanto maior for a participação de um ativo no portfólio dos agentes maior será o grau de exposição dos mesmos a uma eventual perda de capital sobre a retenção desse ativo ou a uma possível frustração das expectativas iniciais a respeito da rentabilidade do mesmo. Em ambos os casos, quanto maior for a participação desse ativo no portfólio dos agentes maior será o risco de inadimplência (default risk). Temos, então, que:

$$
\mathrm{R}_{\mathrm{k}}=\mathrm{R}_{\mathrm{k}}(\mathrm{Ki}) \quad ; \partial \mathrm{R}_{\mathrm{k}} / \partial \mathrm{K}_{\mathrm{j}}>0
$$

$O$ ativo moeda é definido como aquele ativo para o qual $Q_{m}=C_{m}=R_{m}=0$. $O$ prêmio de liquidez da moeda, por outro lado, é máximo e não varia com o aumento de sua quantidade.

Deve-se ter claro qual o papel que a moeda desempenha no portfólio dos agentes. Se os agentes demandam o ativo capital é porque o mesmo proporciona um rendimento monetário explícito sob a forma de quase-rendas; a demanda de moeda advém do fato de que a sua presença no portfólio dos agentes confere ao mesmo flexibilidade de adaptação face a eventos imprevistos. Por exemplo, se o agente se defrontar com uma necessidade não prevista de fundos líquidos para fazer face a um pagamento contratual, a retenção de moeda em portfólio permite que essa necessidade seja rapidamente atendida a um baixo custo. Essa flexibilidade não é possível no caso do ativo capital, pois a utilização do mesmo para esse fim envolve a sua conversão prévia em meio de pagamento. Dada a menor liquidez dessa ativo vis-à-vis a moeda, a perda de capital envolvida nesse processo será tão maior quanto maior for a urgência com a qual se tenha que realizar esse ativo com vistas ao atendimento da necessidade de fundos líquidos ${ }^{11}$.

Consideremos um indivíduo que possua um estoque $\mathrm{W}$ de riqueza, o qual ele deverá alocar entre moeda e capital. Suponhamos, também, que esse indivíduo deseje reter esses ativos por apenas um período, ao final do qual ele irá converter todo o estoque de riqueza em dinheiro. Esse indivíduo deseja escolher as quantidades $\mathrm{K}_{\mathrm{i}}^{*}$ e $\mathrm{M}_{\mathrm{i}}^{*}$ dos ativos capital e moeda, respectivamente, que ele deseja

\footnotetext{
"Devemos observar a diferença entre o papel que a moeda desempenha nos modelos pós-Keynesianos do papel que ele desempenha no modelo de Tobin (1958) de escolha de portfólio. Neste, a função da moeda é minimizar o risco de perda de capital associado à posse de ativos cujo preço de mercado está sujeito a variações em função do comportamento da taxa de juros. Nos modelos pós-keynesianos, a demanda de moeda se origina do fato de que este é o único ativo cujo prazo de realização não tem nenhuma influência sobre o seu preço de mercado, de forma que é o ativo ideal para fazer frente a imprevistos desfavoráveis. Qualquer outro ativo sofreria uma perda de capital no processo de sua conversão em meio de pagamento, perda essa que será tão maior quanto (i) menor for o prazo de realização desse ativo e (ii) menor for o grau de organização do mercado no qual esse ativo é transacionado.
} 
manter em portfólio de forma a maximizar o retorno esperado do mesmo. Segue-se, portanto, que o problema de maximização do indivíduo pode ser apresentado da seguinte forma :

MAX Z $=\left\{\left[\Phi Q_{k}(K i)-C_{k}-R_{k}(K i)+L_{k}\right] K_{i}-P_{k} K_{i}\right\}+\left\{L_{m} M_{i}-P_{m} M_{i}\right\} K_{i}, M_{i}$

s.a $\mathrm{P}_{\mathrm{k}} \cdot \mathrm{K}_{\mathrm{i}}+\mathrm{P}_{\mathrm{m}} \cdot \mathrm{M}_{\mathrm{i}}=\mathrm{W}$

onde : $\mathrm{P}_{\mathrm{k}}$ é o preço spot do ativo capital ; e $\mathrm{P}_{\mathrm{m}}$ é o preço spot do ativo moeda $\left(\mathrm{P}_{\mathrm{m}}=1\right)$.

O primeiro termo em (4) nada mais é do que o lucro esperado resultante do "investimento" na compra do ativo capital. De fato, o termo em colchetes representa o rendimento unitário esperado do ativo capital; o qual é deduzido do investimento inicial na compra do ativo em consideração para se obter o lucro dessa aplicação. De forma análoga, o lucro da aplicação em moeda é dado pela diferença entre o seu "retorno" implícito sob a forma de liquidez e o "investimento" feito inicialmente na aquisição desse ativo.

Deve-se observar também que o indivíduo em consideração não é capaz de influenciar os preços spot dos ativos que mantêm em seu portfólio, ou seja, estamos supondo que prevalece a concorrência perfeita nos mercados dos referidos ativos ${ }^{12}$.

As condições de primeira ordem para a maximização de (4) são dadas por :

$$
\begin{aligned}
& \partial Z / \partial M_{i}=I_{m}-1-\lambda=0 \Rightarrow \lambda=I_{m}-1 \\
& \partial Z / \partial K_{i}=\left\{\Phi Q_{k}-C_{k}-R_{k}+I_{k}\right\}+K_{i}\left\{\Phi\left(\partial Q_{k} / \partial K_{i}\right)-\left(\partial R_{k} / \partial K_{i}\right)\right\}-(1+\lambda) P_{k}=0 \\
& \partial Z / \partial \lambda=P_{k} K_{i}+M_{i}-W=0
\end{aligned}
$$

onde $: \lambda$ é o multiplicador de lagrange ${ }^{13}$.

\footnotetext{
${ }^{12}$ A introdução da hipótese de concorrência imperfeita não traria nenhum resultado qualitativamente diferente dos tesultados obtidos com a hipótese de concorrência perfeita; além do que, como se observa em Licha (1990), a introdução de concorrência imperfeita torna consideravelmente mais complicado, do ponto de vista matemático, a derivação dos estoques de capital e moeda que os indivíduos desejam reter em portfólio. Com base, portanto, no "princípio da simplicidade" de Occan, podemos descartar a hipótese de concorrência imperfeita, concentrando nossa atenção apenas no caso de concorrência perfeita.

${ }_{13} O$ valor de $\lambda$ representa o aumento no valor da função $Z$ em função do aumento de $W$ em uma unidade (Cf. Barro, R \& Sala-i-Martin, X , 1995, pp 493-494), ou seja, o multiplicador de lagrange mostra o aumento dos lucros esperados do portfólio do indivíduo quando o valor de seus ativos aumenta em uma unidade. Segue-se, portanto, que o multiplicador de lagrange mede a contribuição de cada unidade do estoque de riqueza para o retorno total do portfólio do indivíduo em consideração. Esse conceito é análogo ao conceito de "eficiência marginal do capital em geral" (Keynes, 1936, pp. 135-136), ou seja, oferece um padrão de comparação para o indivíduo no momento em que ele está decidindo se vai adquirir uma unidade adicional de moeda ou de capital (Cf. Licha, 1990, p. 5). Em outras palavras, ao decidir se deve ou não fazer um investimento adicional na aquisição de moeda ou de capital, o indivíduo deverá comparar a taxa esperada de retorno desses ativos com o valor de $\lambda$; tal investimento só será realizado se a sua taxa esperada de retorno for igual ou superior a $\lambda$
} 
A equação (5a) mostra que o indivíduo irá investir na aquisição de moeda até o ponto em que a "eficiência marginal do capital em geral" for igual à taxa esperada de retorno sobre o ativo moeda. Essa taxa esperada de retorno nada mais é do que a taxa subjetiva de juros, ou seja, a taxa mínima de retorno que os indivíduos desejam obter para abrir mão de uma unidade do ativo moeda. Como o "prêmio de liquidez" da moeda é constante ${ }^{14}$, segue-se que a quantidade de moeda que os indivíduos desejam reter não é determinada a partir dessa equação (Cf. Licha, 1990, p. 5). Tal afirmação pode ser visualizada por intermédio da figura 1.

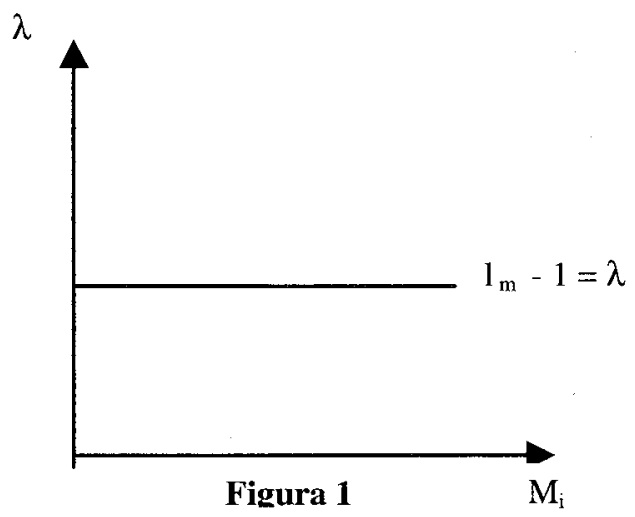

Se definirmos $1_{m}-1=j_{m}$, substituirmos essa definição na equação (5b), temos, após os algebrismos necessários que:

$$
P_{k}=\frac{\left\{\Phi Q_{k}-C_{k}-R_{k}+I_{k}\right\}+K_{i}\left\{\Phi\left(\partial Q_{k} / \partial K_{i}\right)-\left(\partial R_{k} / \partial K_{i}\right)\right\}}{\left(1+j_{m}\right)}
$$

O lado direito da equação (6) nada mais é do que o preço de demanda do ativo capital, ou seja, o preço máximo que o indivíduo está disposto a pagar por uma unidade de capital. O preço de demanda de qualquer ativo nada mais é do que o valor presente do fluxo de rendimentos que se espera obter desse ativo ao longo do período no qual ele é mantido em portfólio (Cf. Keynes, 1936, p. 137). Como estamos supondo que o indivíduo irá manter seus ativos em portfólio por apenas um único período, e que os rendimentos que tais ativos proporcionam só estarão disponíveis ao final do período; segue-se que o preço máximo que o indivíduo estará disposto a pagar pelo ativo capital será igual ao valor dos rendimentos esperados desse ativo descontado pela taxa subjetiva de juros.

\footnotetext{
${ }^{14}$ Segundo Macedo e Silva (1994), a moeda é o único ativo que não está sujeito ao "princípio da rentabilidade esperada decescente", isso porque, por um lado, é o único ativo cujo acúmulo coontínuo no portfólio dos agentes não implica um maior risco de inadimplência em função da ocorrência de eventos imprevistos, dada a sua natureza de meio de pagamento. Por outro lado, como a moeda não é um ativo produtivo, ou seja, como a quase-renda da moeda é igual a zero; segue-se que um aumento na quantidade de moeda no portfólio dos agentes não deverá produzir uma redução no seu rendimento.
} 
Nesse contexto, a equação (6) nos diz que o indivíduo irá demandar o ativo capital até o ponto em que o preço de demanda desse ativo for igual ao seu preço de mercado, isto é, o seu preço spot .

O preço de demanda do ativo capital é inversamente relacionado com a quantidade de capital que o indivíduo possui em seu portfólio, ou seja, quanto mais capital o indivíduo possuir menor será o preço que o indivíduo estará disposto a pagar por uma unidade adicional desse ativo. De fato, diferenciando (6) com respeito a $\mathrm{P}_{\mathrm{k}}$ e $\mathrm{K}_{\mathrm{i}}$ temos :

$$
\partial \mathrm{P}_{\mathrm{k}} / \partial \mathrm{K}_{\mathrm{i}}=\frac{\left\{2\left[\Phi\left(\partial \mathrm{Q}_{\mathrm{k}} / \partial \mathrm{K}_{\mathrm{i}}\right)-\left(\partial \mathrm{R}_{\mathrm{k}} / \partial \mathrm{K}_{\mathrm{i}}\right)\right]\right\}}{\left(1+\mathrm{j}_{\mathrm{m}}\right)}<0 \quad(7)^{15}
$$

A determinação do estoque de capital que o indivíduo deseja reter em portfólio pode ser visualizada por intermédio da figura 2 .

onde :

$\mathrm{P}_{\mathrm{k}}^{\mathrm{d}}$ : preço de demanda do capital

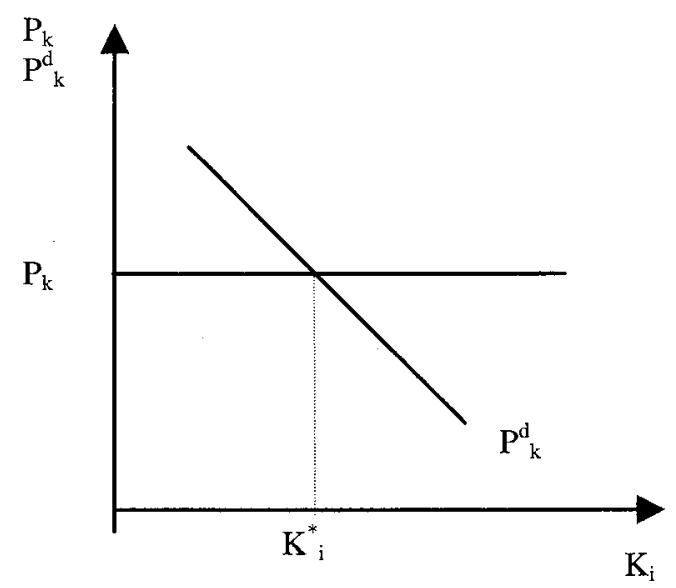

Figura 2

A equação (6) define implicitamente o estoque de capital que os indivíduos desejam reter em portfólio como uma função (i) do preço spot dos ativos de capital, (ii) da taxa subjetiva de juros, (iii) do grau de confiança do indivíduo em suas previsões a respeito da rentabilidade futura do ativo capital e (iv) do "prêmio de liquidez" desse ativo. Temos, então, que :

$$
\mathrm{K}_{\mathrm{i}}^{*}=\mathrm{K}_{\mathrm{i}}\left(\mathrm{P}_{\mathrm{k}}, \mathrm{j}_{\mathrm{m}}, \Phi, \mathrm{I}_{\mathrm{k}}\right) ; \partial \mathrm{K}_{1} \partial \mathrm{P}_{\mathrm{k}}<0, \partial \mathrm{K}_{1} / \partial \mathrm{j}_{\mathrm{m}}<0 ; \partial \mathrm{K}_{1} / \partial \Phi>0, \partial \mathrm{K}_{\mathrm{I}} / \partial \mathrm{I}_{\mathrm{k}}>0
$$

Uma vez determinado o estoque de capital que o indivíduo deseja reter em portfólio, a restrição orçamentária irá determinar qual é a quantidade de moeda que será demandada por esse agente. Temos, então, que :

$$
\mathrm{M}_{\mathrm{i}}^{*}=\mathrm{W}-\mathrm{P}_{\mathrm{k}^{*}} \cdot \mathrm{K}_{\mathrm{i}}^{*}
$$

${ }^{15}$ Para obter esse resultado tivemos que supor $\partial^{2} \mathrm{Q}_{\mathrm{k}} / \partial \mathrm{K}_{\mathrm{i}}{ }_{\mathrm{i}}=\partial^{2} \mathrm{R}_{\mathrm{k}} / \partial \mathrm{K}^{2}{ }_{\mathrm{i}}=0$, ou seja, que as funções $\mathrm{Q}_{\mathrm{k}}\left(\mathrm{K}_{\mathrm{i}}\right)$ e $\mathrm{R}_{\mathrm{k}}\left(\mathrm{K}_{\mathrm{i}}\right)$ são lineares $\mathrm{em} \mathrm{K}_{\mathrm{j}}$. 


\section{A determinação do preço Spot dos ativos de capital e a não-neutralidade da moeda no longo prazo ${ }^{16}$}

Na seção anterior se analisou a decisão individual de alocação do estoque de riqueza entre dois ativos, moeda e capital, tomando-se como dados os preģos de tais ativos. Resta agora saber como os preços de tais ativos, em particular, o preço spot do ativo capital é determinado.

Ao longo da História do Pensamento Econômico surgiram dois métodos para se lidar com a questão da determinação dos preços dos bens e serviços em geral. O primeiro método consiste no equilíbrio parcial marhalliano. Este método se fundamenta na desconsideração de todo o tipo de inter-relação existente entre os diversos mercados que compõem uma economia qualquer. Em outras palavras, ao se analisar a determinação do preço de um bem em particular, deve-se desconsiderar a influência que os demais mercados têm sobre a determinação desse preço, bem como a repercussão que este tem sobre os demais mercados.

O segundo método consiste no equilíbrio geral walrasiano. Ao contrário do equilíbrio parcial, o equilíbrio geral leva em conta as inter-relações existentes entre os diversos mercados que compõem uma economia. Sob esse aspecto ele seria mais realista e apropriado para se analisar a determinação dos preços dos ativos do que o método de equilíbrio parcial. Contudo, como é observado por Chick (1993, p. 17), se o equilíbrio parcial marshalliano desconsidera as inter-relações existentes entre os diversos mercados; o equilíbrio geral walrasiano desconsidera a existência do tempo e da incerteza. De fato, nos modelos de equilíbrio geral Arrow-Debreu, a incorporação do tempo é feita unicamente através da indexação dos diversos bens e serviços com base na data na qual eles serâo entregues; sendo que, todas as transações envolvendo tais mercadorias são efetuadas num único instante do tempo (Cf. Farmer, 1993, p. 80). Como todas as transações ocorrem no mesmo instante do tempo, não existe espaço para que os indivíduos possam demandar moeda (Cf. Hahn, 1981); uma vez que a retenção de moeda só será uma atitude racional por parte dos agentes econômicos numa economia seqüencial, isto é, numa economia na qual as transações são efetuadas ao longo de uma sequiência de períodos.

Pode-se argumentar, no entanto, que os modelos de equilíbrio geral ArrowDebreu não são incompatíveis com a existência de seqüencialidade nas transações. De fato, se os agentes puderem transacionar um ativo - por exemplo, se os agentes puderem emprestar ou tomar emprestado uns dos outros - entre os períodos nos quais os mercados estão "abertos", segue-se que as restrições orçamentárias de cada uma desses agentes para os diversos períodos podem ser colapsadas em um única restrição orçamentária intertemporal (Cf. Farmer, 1993, p.81).

\footnotetext{
${ }^{16}$ A argumentação apresentada a seguir é baseada em Davidson (1978) e Carvalho (1992)
} 
Nesse caso, a solução de equilíbrio encontrada para o modelo no qual os mercados abrem apenas em um único período é idêntica à solução encontrada no modelo no qual os mercados abrem em todos os períodos.

Contudo, como bem observado por Farmer (Ibid, p.81), essa argumentação só é válida num contexto no qual os agentes têm informação a respeito da distribuição de probabilidades dos eventos futuros. Em outros termos, tal argumentação é incompatível com o conceito Keynesiano de incerteza. Sendo assim, o método de equilíbrio geral será descartado em benefício do método de equilíbrio parcial; fazendo-se uma ressalva, contudo, para o manifesto irrealismo deste último.

Tendo definido o método de análise a ser empregado, podemos passar para a análise da determinação do preço dos ativos de capital.

O preço dos ativos de capital, como o preço de qualquer bem ou serviço, é determinado no ponto em que a demanda e a oferta de mercado desses ativos se equalizam. No curto prazo, o estoque existente de capital é fixo, ou seja, a função oferta do ativo capital é representada por uma reta vertical no plano $<\mathrm{P}_{\mathrm{k}}, \mathrm{K}>$ ( Figura 3). No longo-prazo, contudo, o estoque de capital pode variar livremente, devido à possibilidade de se encomendar novos bens de capital junto às fábricas que produzem tais bens. Supondo que as firmas que produzem operam com retornos de escala constantes; segue-se que o preço de oferta dos referidos ativos não irá variar com a quantidade produzida de capital. Em resumo, a oferta de capital é completamente inelástica no curto prazo; mas é perfeitamente elástica no longo prazo.

A demanda de mercado dos ativos de capital é obtida através da agregação das demandas individuais dos ativos em questão. Temos, então, que :

$$
K^{d}=\sum K_{i}^{*}\left(P_{k}, j_{m}, \Phi, I_{k}\right) \quad ; i=1, \ldots, n
$$

onde : $\mathrm{K}^{\mathrm{d}}$ é a demanda de mercado dos ativos de capital, $n$ é o número de demandantes desse ativo.

onde :

$\mathrm{K}^{\prime}$ : estoque de capital existente no curto prazo.

$\mathrm{K}^{*}$ : estoque de capital de equilíbrio de longo prazo.

$\mathrm{P}^{*}{ }_{\mathrm{k}}$ : preço spot

$\mathrm{P}^{\mathrm{s}}{ }_{\mathrm{k}}$ : preço de oferta.

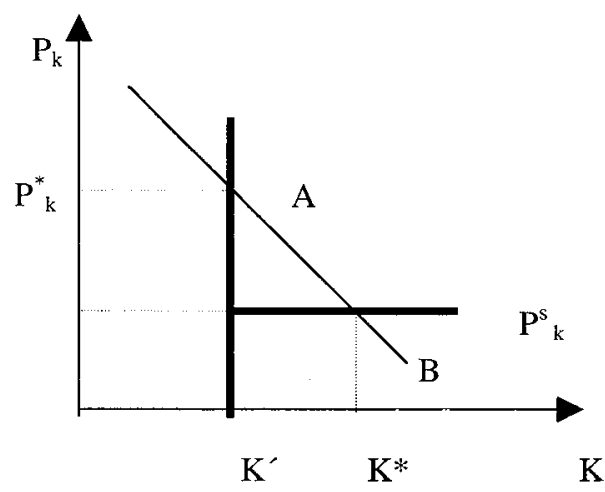

Figura 3 
Na Figura 3 observa-se que a curto prazo, o preço dos ativos de capital deve se ajustar de forma a fazer com que os indivíduos fiquem dispostos a reter em seus portfólios todo o estoque de capital que existe na economia. O preço spot assim determinado só por pura coincidência será igual ao preço de oferta dos ativos de capital. No ponto A observa-se que o preço spot é maior do que o preço de oferta dos ativos em consideração. Isso significa que os agentes econômicos estão dispostos a pagar um preço mais elevado pelos ativos de capital do que o preço que custa para produzi-los. Essa situação deverá estimular a produção de novos bens de capital (Cf. Carvalho, 1992, pp.120-129). Os empresários continuarão investindo na compra de novos bens de capital até o ponto em que o preço spot desses ativos for igual ao preço de oferta dos mesmos. Neste ponto o investimento será igual a zero, e estará determinado o estoque de capital de equilíbrio de longo prazo ( ponto B).

Resta, por fim, analisar a proposição de Keynes de que a moeda é nãoneutra no longo prazo. De acordo com Keynes :

The theory which I desiderate would deal ... with an economy in which money plays a part of its own and affects motives and decisions and is, in short, one of the operative factors in the situation, so that the course of the events cannot be predicted, either in the long period or in the short (grifo nosso), without a kwowledge of the behavior of money between the first state and the last. (CWJMK, XIII, pp. 408-9).

A moeda é dita não-neutra sobre as variáveis reais no longo prazo se e somente se variações do estoque de moeda existente na economia forem capazes de produzir variações no estoque de capital de equilíbrio de longo prazo da economia em consideração.

Para demonstrar a não-neutralidade da moeda, consideremos que o "prêmio de liquidez" dos ativos de capital é, em larga medida, determinado pelo estado de liquidez prevalecente na economia. Esse estado de liquidez, por seu turno, depende da relação entre o estoque de haveres monetários existentes na economia e o estoque de haveres não-monetários. Isso significa que quanto maior for o estoque de haveres monetários relativamente ao estoque de haveres não-monetários, mais "fácil" deverá ser a conversão destes últimos em meio de pagamento, ou seja, maior deve ser a liquidez dos ativos nãomonetários. Essa hipótese pode ser formalizada do seguinte modo :

$$
\gamma=\gamma(\mathrm{M} / \mathrm{K}) ; \gamma^{\prime}>0 \quad(10)^{17}
$$

\footnotetext{
${ }^{17}$ Uma hipótese semelhante a essa é feita por Minsky (1975, pp.102-105) no contexto da teoria do investimento. De acordo com Minsky, o fator de capitalização aplicado à determinação do valor presente dos rendimentos de um ativo de capital $\left(\mathrm{C}_{\mathrm{k}}\right)$ seria apenas uma fração do valor do fator de capitalização utilizado na determinação do valor presente dos rendimentos dos ativos financeiros $\left(C_{1}\right)$, ou seja, $C_{k}=\mu$ $\mathrm{C}_{1}, 0<\mu<1$. Um aumento da oferta de moeda seria capaz não só de aumentar o valor de $\mathrm{C}_{1}$, como também pode mudar a relação entre $\mathrm{C}_{\mathrm{k}}$ e $\mathrm{C}_{1}$.
} 
A equação (10) apresenta o fator de proporcionalidade entre o "prêmio de liquidez" dos ativos de capital e o "prêmio de liquidez" da moeda como uma função da relação entre o estoque de moeda e o estoque de ativos de capital. Quanto maior for o estoque de moeda relativamente ao estoque de ativos de capital existente na economia, maior será, ceteris paribus, o estado de liquidez prevalecente na economia; ou seja, mais fácil será a conversão dos ativos de capital em meio de pagamento, aumentando, com isso, o seu "prêmio de liquidez".

Suponhamos, agora, que as autoridades monetárias resolvam aumentar o estoque de moeda existente na economia através de uma operação de open-market. Segue-se, portanto, que DM = - DK, ou seja, o estoque de capital existente na economia irá se reduzir na mesma proporção na qual o estoque de moeda aumenta. Nos termos da figura 3, essa política deverá ter dois efeitos: em primeiro lugar, ele deslocará a curva que representa a quantidade de capital que a economia possui no curto prazo para a esquerda; produzindo, portanto, um aumento do preço spot dos ativos de capital. Como resultado da elevação do preço spot desses ativos, segue-se que a diferença entre o preço spot e o preço de oferta dos referidos ativos deve aumentar, estimulando os empresários a investir mais. Portanto, os efeitos de curto prazo da política monetária expansiva são os seguintes: aumento do preço spot dos ativos de capital - ou seja, um aumento da cotação das ações nas bolsas de valores - seguido por um aumento do dispêndio na compra de bens de capital, isto é, um aumento do investimento agrega$\mathrm{do}^{18}$.

Em segundo lugar, a política monetária expansiva, ao alterar o estado de liquidez existente na economia, deverá deslocar a curva de demanda de mercado dos ativos de capital para cima ( Figura 4). Isso decorre do fato de que o aumento do estado de liquidez da economia - medido pela relação $\mathrm{M} / \mathrm{K}$ - à medida que aumenta o "prêmio de liquidez" dos ativos de capital vis-à-vis o "prêmio de liquidez da moeda", irá aumentar a taxa de retorno dos ativos de capital; estimulando, dessa forma, a substituição de moeda por ativos de capital no portfólio dos agentes. Conseqüentemente, se define um novo ponto de equilíbrio de longo prazo ( ponto C da Figura 4), no qual o estoque de capital de equilíbrio é mais elevado. Em outras palavras, a operação de open-market conduzida pelas autoridades monetárias, ao alterar o estado de liquidez prevalecente na economia, foi capaz de deslocar as preferências dos investidores em direção aos ativos de capital. Dessa

\footnotetext{
${ }^{18} \mathrm{O}$ aumento do investimento agregado explica a não-neutralidade da moeda no curto prazo. De fato, esse aumento do investimento irá produzir um aumento do volume de demanda efetiva, por intermédio do multiplicador do investimento, o qual resultará em um aumento do nível de emprego e de produção de equilíbrio, dado o nivel de salário nominal e as condições técnicas de produção.
} 
forma, o estoque de capital de equilíbrio de longo prazo aumentou relativamente a situação inicial na qual o estado de liquidez era menor. Seguese, portanto, que a política monetária é não-neutra sobre as variáveis reais da economia, mesmo no longo-prazo.

\section{Conclusão}

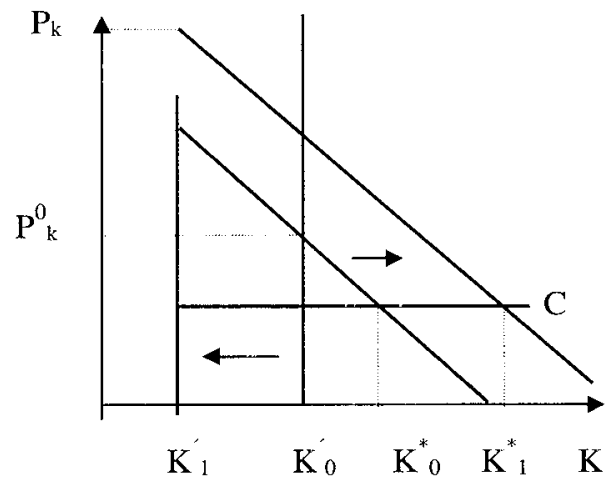

Ao longo do presente artigo, apresentamos os microfundamentos Keynesianos da não-neutralidade da moeda no longo prazo. Foi demonstrado que a proposição da não-neutralidade da moeda no longo prazo deve ser analisada no contexto de um modelo de escolha de portfólio no qual os agentes levem em conta, no momento em que estão decidindo a respeito de que ativos manter em carteira, todos os atributos dos diferentes ativos. Em particular, deve-se considerar explicitamente o atributo "prêmio de liquidez", o qual é ignorado pelas abordagens convencionais a respeito da composição de portfólio, que tendem a considerar esse atributo como um sinônimo do "prêmio de risco".

A inclusão do "prêmio de liquidez" na decisão de escolha de portfólio tem como resultado a idéia de que as operações de open-market são capazes de alterar o estoque de capital de equilíbrio de longo prazo de uma economia; tornando, portanto, a moeda não-neutra no longo prazo.

Deve-se observar que a não-neutralidade da moeda no modelo Keynesiano de escolha de portfólio não se deriva de nenhum tipo de imperfeição ou rigidez nominal. De fato, o modelo Keynesiano de escolha de portfólio é perfeitamente compatível com a existência de concorrência perfeita nos mercados dos diferentes ativos; bem como, não se baseia na hipótese de que a taxa nominal de retorno da moeda é fixada institucionalmente, tal como ocorre em outros modelos de inspiração Keynesiana, como, por exemplo, o modelo de escolha de portfólio de James Tobin. Tudo o que é necessário para fundamentar a não-neutralidade da moeda no longo prazo é a idéia de que, sob incerteza 
forte, os indivíduos valorizam a posse de ativos líquidos; estando, portanto, dispostos a sacrificar algum rendimento monetário em troca da "conveniência" e da "segurança" proporcionadas pela posse de ativos líquidos.

Nesse contexto, a política monetária é capaz de influenciar o estoque de capital de equilíbrio de longo prazo à medida que ela pode alterar a relação entre o "prêmio de liquidez" da moeda e o "prêmio de liquidez" dos ativos de capital. Em concreto, uma política monetária expansiva pode aumentar o "prêmio de liquidez" dos ativos de capital, aumentando, dessa forma, a taxa de retorno desses ativos. Tal fato, irá estimular a substituição de moeda por ativos de capital; o que irá aumentar o estoque de capital de equilíbrio de longo prazo dessa economia.

D.O.G

\section{Referências bibliográficas}

BARRO, R \& SALA-I-MARTIN, X. Economic growth .: Nova Iorque: McGraw-Hill, 1995

CARVAL.HO, F. C. Mr Keynes and the Post Keynesians. Aldershot: Edward Elgar, 1992.

CHICK, V. Macroeconomia após Keynes: um reexame da Teoria Geral. Rio de Janeiro: Forense, 1993.

DAVIDSON, P. Money and the real world. Londres: Macmillan,1978.

FARMER, R. E. The Macroeconomics of self-fulfilling prophecies. Cambridge: MIT Press 1993

HAHN, F. Money and inflation. Cambridge: Cambridge University Press, 1981.

HARRIS, L. Teoria monetária. México: Fondo de Cultura, 1981.

HICKS, J.R. The crisis in keynesian economics. Nova Iorque: Basic Books, 1974.

-Dinero, interés y salários. México: Fondo de Cultura, 1989.

KAHN, R. (1954). Some notes in liquidity preference. In Sellected essays on employment and growth. Cambridge: Cambridge University Press, 1972.

KALECKI, M. (1954). Teoria da Dinâmica Econômica. Nova Cultural : São Paulo 1983.

KEYNES, J. M .(1936). The general theory of employment, interest and money.: Londres: Macmillan, 1973.

1973. The collected writings of John Maynard Keynes. Londres: Macmillan : [ no texto $C W J M K$ ].

KREGEL, J. 1998. Aspects of a post keynesian theory of finance. Journal of Post Keynesian Economics [ forthcoming].

LICHA, A. 1990. Sobre a decisão de aplicação de capital em Keynes. Mimeo, Campinas. MACEDO E SILVA, A.C. 1994. Uma introdução a teoria macroeconômica. Mimeo, IE-Unicamp.

McCALLUN, B. 1996. International monetary economics. Oxford University Press : Nova Yorque.

MINSKY, H.P. (1975). John Maynard Keynes. Londres: Macmillan 
MODIGLIANI, F. 1944. Liquidity preference and the theory of interest and money. Econométrica, 12.

OREIRO, J.L. 1997. Flexibilidade salarial, equilíbrio com desemprego e desemprego de desequilíbrio. Revista Brasileira de Economia, $n^{\circ} 3$.

1998 Incerteza, retornos crescentes e comportamento convencional: algumas implicações para a teoria keynesiana do investimento. Anais do $X X V$ Encontro Nacional de Economia, Vitória.

PIGOU, A.C . 1943. The classical stationary state. Economic Journal, v. 53, n.212.

ROMER, D. 1996. Advanced macroeconomics. Nova Iorque: McGraw-Hill .

SACHS, J \& LARRAIN, F 1995. Macroeconomia. Makron Books: São Paulo.

SARGENT, T. 1987. Macroeconomic theory. Nova Iorque: Academic Press.

SIMON, H. 1982. Models of bounded rationality. MIT Press : Cambridge (mass.)

STUDART, R. 1995. Investment Finance in Economic Development. Nova Yorque: Routledge.

TOBIN, J. (1955). A dynamic agregative model. In Essays in Economics, v. 1: Macroeconomics. Cambridge: MIT Press, 1987.

(1958). Liquidity preference as a behaviour toward risk. In: Essays in economics, v. 1: Macroeconomics. Cambridge: MIT Press1987.

(1969). A general equilibrium approach to monetary theory. In Essays in economics, v. I : Macroeconomics. Cambridge: MIT Press, 1987.

VERCELLI, A.. Methodological foundations of macroeconomics : Keynes \& Lucas. Cambridge: MIT Press, 1991. 1997. Liquidity preference and option values. Siena: Universitá di Siena (Mimeo). 